\title{
Reye-like syndrome following treatment with the pantothenic acid antagonist, calcium hopantenate
}

\author{
S NODA, ${ }^{*}$ H UMEZAKI, ${ }^{*}$ K YAMAMOTO,* ${ }^{*}$ T ARAKI, $*$ T MURAKAMI, $\dagger$ N ISHII \\ From the Department of Neurology* and Internal Medicine, $\dagger$ Kyushukoseinenkin Hospital, and Department of \\ Pathology, $\ddagger$ University of Occupational and Environmental Health, School of Medicine, Kitakyushu, Japan
}

SUMMARY Three senile patients developed fatal acute encephalopathy while receiving calcium hopantenate. The clinical, biochemical, and pathological picture was similar to Reye's syndrome. Calcium hopantenate is a pantothenic acid antagonist. The serum levels of calcium hopantenate were high in coma, and that of pantothenic acid examined in one patient was lowered. Evidence obtained indicated that the Reye-like syndrome might be caused by calcium hopantenate possibly due to the induction of pantothenic acid deficiency.

Calcium hopantenate, calcium D-(+)-4-(2,4dihydroxy-3,3-dimethyl-butyramido) butyrate, hemihydrate is obtained by substituting the $\beta$-alanine moiety of pantothenic acid for gamma aminobutyric acid (GABA) and has a GABAergic effect on the central nervous system. ${ }^{1}$ It has been available only in Japan (since 1978) for treatment of diminished reactivity in organic brain diseases of children and adults. $^{2}$

Between 1983 and 1985, 11 Japanese children were reported to have developed a Reye-like syndrome in association with administration of calcium hopantenate. ${ }^{3-6}$ The disorder has not been recognised in adults and little is known about the pathogenesis. During the past 2 years, we have observed three senile patients who developed fatal Reye-like syndrome while receiving calcium hopantenate. A representative patient (case 1) is described and the possibility is discussed that the disorder may be due to pantothenic acid deficiency caused by calcium hopantenate, since this agent is a pantothenic acid antagonist. ${ }^{7}$

\footnotetext{
Address for reprint requests: Dr S Noda, Department of Neurology, Kyushukoseinenkin Hospital, Kishinoura, Yahatanishiku, Kitakyushu, 806, Japan.
}

Received 4 August 1987 and in revised form 20 October 1987. Accepted 26 October 1987

\section{Case report}

The patient (case 1) was a 72 year old female with multi infarct dementia. Four months before our examination she had been started on a regimen of calcium hopantenate therapy $(37 \mathrm{mg} / \mathrm{kg} / \mathrm{d})$ ). One day before the examination, with no prodromal symptoms, she developed severe nausea and vomiting, and then became stuporous. On examination her vital signs were as follows: temperature $35.6^{\circ} \mathrm{C}$; pulse, 96 beats $/ \mathrm{min}$, respiration, $36 / \mathrm{min}$, and $\mathrm{BP}, 160 / 70 \mathrm{mmHg}$. She was deeply comatose and unresponsive to noxious stimuli. Pupils were small and reactive to light. Her upper limbs were flaccid and her lower limbs were spastic in flexion, a condition present since the age of 70 years. Deep tendon reflexes were brisk in all four extremities. Hepatosplenomegaly was not observed.

Laboratory values at the time of coma included: arterial $\mathrm{pH}, 7.04 ; \mathrm{PaCO}_{2}, 12 \mathrm{mmHg} ; \mathrm{PaO}_{2}, 152 \mathrm{mmHg} ; \mathrm{HCO}_{3}{ }^{-}$, $5 \mathrm{mmol} / \mathrm{l}$; base excess, $-22 \mathrm{mmol} / 1$; blood glucose, $1.0 \mathrm{mmol} / 1$ (normal, 4.2 to 6.4 ); blood ammonia, $323 \mu \mathrm{mol} / 1$ (normal, 7 to 38 ); serum lactate, $22.1 \mathrm{mmol} / 1$ (normal, 0.4 to 1.6); serum pyruvate, $0.55 \mathrm{mmol} / 1$ (normal, 0.03 to 0.10 ); BUN, $12.1 \mathrm{mmol} / 1$ (normal, 1.8 to $7 \cdot 8$ ); serum creatinine, $124 \mu \mathrm{mol} / 1$ (normal, 44 to 133 ); serum $\mathrm{Na}, 133 \mathrm{mmol} / \mathrm{l}$; serum $\mathrm{K}, 5.0 \mathrm{mmol} / \mathrm{l}$; serum chloride, $101 \mathrm{mmol} / \mathrm{l}$; serum uric acid, $0.8 \mathrm{mmol} / 1$ (normal, 0.12 to 0.36 ); serum creatine kinase (CK), 375 IU/1 (normal, 39 to 167); serum bilirubin, $10.1 \mu \mathrm{mol} / 1$ (normal, 3.4 to 17 ); serum glutamic oxaloacetic transaminase (SGOT), 24 IU/l (normal, 12 to 34); and serum glutamic pyruvic transaminase (SGPT), 21 IU/1 (normal, 5 to 29). High lactic acid and dicarboxylix acid levels were noted in the urine. Urine ketone body concentration was 


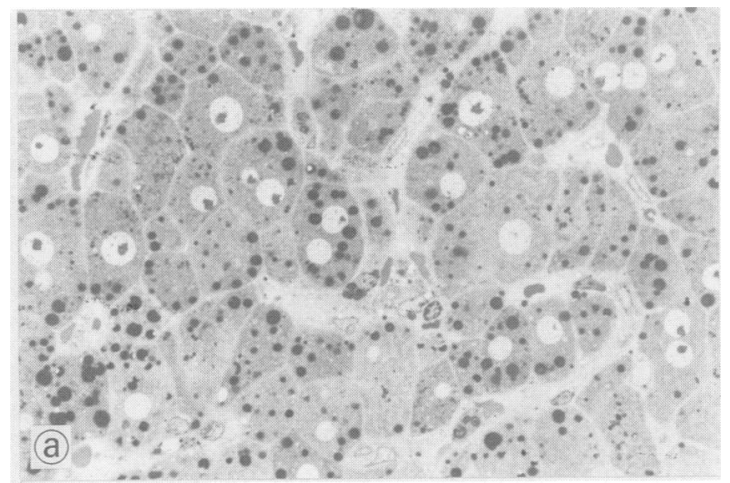

Fig (a) Light micrograph of liver biopsy specimen. Note microvesicular lipid accumulation in hepatocytes. (Toluidine Blue stain; $\times 400$ ). (b) Electron micrograph of liver biopsy specimen. Note elongated mitochondria containing crystalloid material. $(\times 13600)$.

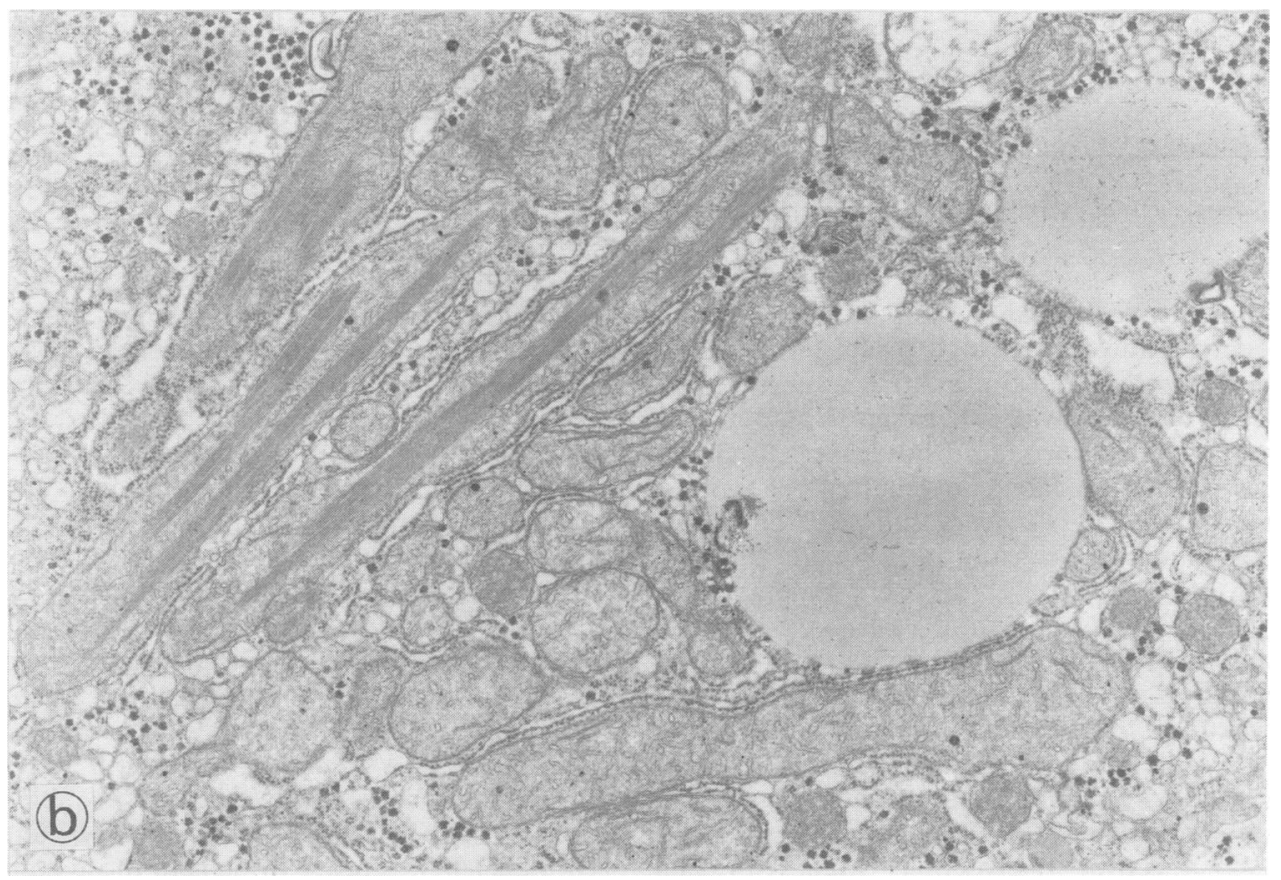

low. Serum calcium hopantenate level was $22 \cdot 2 \mu \mathrm{mol} / 120$ hours after cessation of administration of the drug. Serum pantothenic acid level was low at $0.36 \mu \mathrm{mol} / 1$ (normal, 1.73 to 3.19). A CT scan of the brain showed multiple lacunar infarcts. Sodium bicarbonate and glucose were given IV without benefit. Percutaneous liver biopsy 24 hours after the onset of encephalopathy revealed microvesicular lipid accumulation (fig, a). Electron microscopic examination revealed swollen and pleomorphic mitochondria, distorted and lost cristae, and crystalloid inclusions (fig, b). The patient died 44 hours after the onset of stupor. Postmortem examination was performed. Significant pathological findings were confined to the brain and liver. The brain revealed multiple lacunar infarcts, mainly in the frontal white matter. Most lesions were old. Penetrating small arteries and arterioles exhibited diffuse fibrosis, as well as hyaline medial and adventitial thickening. Cerebral oedema was absent. The liver weighed $900 \mathrm{~g}$ and showed fatty changes, as seen in the biopsy specimen.

\section{Discussion}

Our three senile patients developed acute nausea and vomiting, followed by stupor and coma, while receiving calcium hopantenate for approximately 4 months. All died within $\mathbf{4 8}$ hours after onset of the encephalopathy. The clinical, biochemical, and pathological findings of the three cases are similar (table) and resemble Reye's syndrome. ${ }^{8}$. However, our subjects differed from those with Reye's syndrome, especially in the absence of raised liver transaminase levels. In addition, cerebral oedema was not observed, which is a fairly constant feature of Reye's syndrome. 
Table Summary of clinical, biochemical and pathological features

\begin{tabular}{|c|c|c|c|}
\hline Clinical characteristics & Case 1 & Case 2 & Case 3 \\
\hline $\begin{array}{l}\text { Age (yr)/sex } \\
\text { Body weight }(\mathrm{kg}) \\
\text { Illness } \\
\text { Duration of calcium hopantenate therapy (days) } \\
\text { Dose of calcium hopantenate }(\mathrm{mg} / \mathrm{kg} / \mathrm{day}) \\
\text { Hypothermia } \\
\text { Serum calcium hopantenate level in coma }(\mu \mathrm{mol} / \mathrm{l}) \\
\text { Serum pentathenic acid level }(1 \cdot 73 \text { to } 3 \cdot 19 \mu \mathrm{mol} / \mathrm{l}) \\
\text { Metabolic acidosis } \\
\text { Lacticemia } \\
\text { Hypoglycemia } \\
\text { Leukocytosis } \\
\text { Hyperammonemia } \\
\text { Rise in CK } \\
\text { Hyperamylasemia } \\
\text { Rise in bilirubin } \\
\text { Rise in blood urea nitrogen } \\
\text { Rise in creatinine } \\
\text { Hyperuricemia } \\
\text { Rise in SGOT \& SGPT } \\
\text { Outcome } \\
\text { Necropsy }\end{array}$ & $\begin{array}{l}72 / \mathrm{F} \\
41 \\
\text { MI } \\
121 \\
37 \\
+ \\
22 \cdot 2 \\
0 \cdot 36 \\
++ \\
++ \\
++ \\
\text { ND } \\
++ \\
+ \\
- \\
- \\
+ \\
+ \\
++ \\
\overline{+} \\
\text { died } \\
\text { fatty liver }\end{array}$ & $\begin{array}{l}68 / \mathrm{F} \\
52 \\
\text { PI } \\
120 \\
58 \\
++ \\
13 \cdot 6 \\
\mathrm{ND} \\
++ \\
\mathrm{ND} \\
++ \\
++ \\
\mathrm{ND} \\
\mathrm{ND} \\
++ \\
+ \\
+ \\
+ \\
\text { ND } \\
- \\
\text { died } \\
\text { fatty liver, pancreatitis }\end{array}$ & $\begin{array}{l}67 / \mathrm{M} \\
45 \\
\text { MI } \\
124 \\
33 \\
+ \\
7 \cdot 8 \\
\text { ND } \\
++ \\
++ \\
++ \\
++ \\
\text { ND } \\
++ \\
+ \\
+ \\
+ \\
+ \\
++ \\
\overline{+} \\
\text { died } \\
\text { not done }\end{array}$ \\
\hline
\end{tabular}

MI = multiple cerebral infarction; PI = putaminal infarction; ND = not determined; $-=$ absent; $+=$ minimal; $++=$ moderate to marked. Normal value of pantothenic acid shown in parenthesis.

The pharmacological data on calcium hopantenate ${ }^{2}$ indicate that high serum levels of the agent were present in our three patients during coma. In previous reports, large experimental amounts of calcium hopantenate produced fatty livers in chicks and dogs. ${ }^{79}$ Eleven Japanese children, age range between 9 months and 10 years, suffered from Reyelike syndrome during calcium hopantenate therapy, and seven of them died. ${ }^{3-6}$ Six were male and five female. The dosage was from $0.5 \mathrm{~g}$ to $3.0 \mathrm{~g}$ per day. The duration of administration varied from 15 days to 15 months with a mean of 160 days. The clinical and biochemical features were similar to those found in our patients, except that in the children an elevated transaminase was found. Post-mortem examination revealed microvesicular fatty changes of the liver and kidney. ${ }^{4-6}$ Electron microscopic studies in one patient ${ }^{5}$ showed mitochondrial abnormalities that are associated with Reye's syndrome. ${ }^{10}$ After the appearance of these reports, ${ }^{3-6}$ calcium hopantenate was rarely administered to children, and the occurrence of the syndrome diminished. Our findings, and the reports of cases in children point to calcium hopantenate as the cause of the Reye-like syndrome.

Calcium hopantenate has a structural formula similar to that of pantothenic acid and is a pantothenic acid antagonist. ${ }^{7}$ The activity is three times more potent than that of omega-methyl pantothenic acid, which is a well-studied pantothenic acid antagonist. ${ }^{711}$ High serum levels of calcium hopantenate and low levels of pantothenic acid in case 1 suggest that the drug may reduce the concentration of pantothenic acid by an unknown mechanism. In addi- tion, calcium hopantenate may inhibit utilisation of pantothenic acid in the tissue because it is concentrated mainly in the liver following oral administration. ${ }^{12}$ Liver is therefore presumed to be more affected by pantothenic acid deficiency than are other organs. ${ }^{13}$ The fatty livers in the chicks and dogs produced by calcium hopantenate were prevented by ad- 흘 dition of pantothenic acid. ${ }^{79}$ On the basis of these data,.we suggest the possibility that the pathogenesis of the Reye-like syndrome may be due to pantothenic acid deficiency produced by calcium hopantenate.

Pantothenic acid is a constituent of coenzyme A $(\mathrm{CoA})$ and the level of $\mathrm{CoA}$ is greatest in liver mitochondria. ${ }^{14} \mathrm{CoA}$ serves as a cofactor to yield important compounds in the tricarboxylic cycle, such as acetyl-CoA and succinyl-CoA. In theory, pantothenic acid deficiency appears to deplete those compounds and to inhibit the tricarboxylic cycle, which may produce the Reye-like syndrome. A similar deficiency mechanism may be involved in fatty-liver-and-kidney syndrome of fowls, ${ }^{15}$ which resembles Reye's syndrome and is believed to result from a deficiency of biotin.

In animals, the classic symptoms of pantothenic acid deficiency vary according to the species. ${ }^{16}$ The work of Schaefer et $a l^{17}$ is of interest. These authors described pantothenic acid deficiency in dogs as being characterised by sudden prostration or coma, vomiting, convulsions, hypoglycaemia and fatty livers, all signs that resemble Reye's syndrome. After administration of a diet low in pantothenic acid, together with a pantothenic acid antagonist, omega-methyl pantothenic acid, no Reye-like syndrome was reported in 
human investigations. ${ }^{1819}$ However, these results do not rule out our hypothesis, because omega-methyl pantothenic acid is less potent than calcium hopantenate, and the cited studies are limited in the dose used and the duration of the administration.

The hepatoxicity of calcium hopantenate may be another possible explanation for the disorder. However the $L D_{50}$ of the agent is $5.72 \mathrm{~g} / \mathrm{kg}$ and that of pantothenic acid is $2.49 \mathrm{~g} / \mathrm{kg} .{ }^{19}$ Pantothenic acid is believed to be nontoxic; as much as $10 \mathrm{~g}$ can be given daily to men for 6 weeks without producing symptoms. ${ }^{20}$ Therefore, a toxic aetiology seems unlikely.

We thank Professor A Horie, Dr S Fukuyama, Dr K Kawamura, Dr S Honda and Dr Y Masuda for their advice and support.

\section{References}

1 Nishizawa $Y$, Kodama T, Tsujino G. Effect of $\gamma$-aminobutyric acid derivatives, especially homopantothenic acid, on excitability of the brain. $J$ Vitaminol 1968;14:331-44.

2 Tanabe Pharmaceutical Company. HOPATE ${ }^{\text {in }}$ interview form. April 30, 1986.

3 Sugimoto T, Yasuhara Y, Nishida N, et al. Acute encephalopathy in three children associated with calcium hopantenate. No To Hattatsu (Jpn) 1983; 15:258-9.

4 Togashi K, Miura Y, Ishiyama S, et al. Two autopsied cases of sudden death associated with calcium hopantenate. Brain Develop (Tokyo) 1984;6:167.

5 Tsutsui Y, Shirasawa H, Oka S. An autopsied case of Reye's syndrome occurred during administration of calcium hopantenate. Saishin-Igaku 1984;39:1679-85.

6 Sugimoto T, Nishida N, Wu M, et al. Drugs and Reyelike syndrome: calcium hopantenate. $J$ Pediatr Pract (Jpn) 1986;49:1014-9.

7 Matsuzaki F. The antagonistic action of homopantothenic acid against pantothenic acid.
Vitamins (Jpn) 1965;32:245-59.

8 Reye RDK, Morgan G, Baral J. Encephalopathy and fatty degeneration of the viscera: a disease entity in childhood. Lancet 1963;ii:749-52.

9 Nishizawa Y. Studies on homopantothenic acid in monkeys and dogs. Vitamins (Jpn) 1967;36:93-4

10 Partin JC, Schubert WK, Partin JS. Mitochondrial ultrastructure in Reye's syndrome (encephalopathy and fatty degeneration of the viscera). $N$ Engl $J$ Med 1971;285:1339-43.

11 Ariyama H, Kimura S. Studies on pantothenic acid antagonist. J Vitaminol 1960;6:52-61.

12 Nakamura S, Takashima T, Sato Y. Studies on the distribution of radioisotopes by whole body autoradiography: the fate of ${ }^{14} \mathrm{C}$-HOPA in rats and mice. Vitamins (Jpn) 1972;45:193-200.

13 Danford DE, Munro HN. The liver in relation to the B vitamins. In: Arias IM, Popper $\mathrm{H}$, Schachter D, Shafritz DA, eds. The Liver; Biology and Pathology. New York: Raven Press, 1982:380-1.

14 Wright LD. Pantothenic acid. In: Hegsted DM, Chichester CO, Darby WJ, McNutt KW, Stalvey RM, Stotz EH, eds. Present Knowledge in Nutrition. Washington DC: The Nutrition Foundation. 1976: 226-31.

15 Wight PAL, Siller WG, Evans AJ, et al. Reye's syndrome of children and the fatty-liver-and-kidney syndrome of chickens. Lancet 1975;i:1339.

16 Novelli GD. Metabolic function of pantothenic acid. Physiol Rev 1953;33:525-43.

17 Schaeffer AE, Mckibbin JM, Elvehjem CA. Pantothenic acid deficiency study in dogs. $J$ Biol Chem 1942;143:321-30.

18 Lubin R, Daun KA, Bean WB, et al. Studies of pantothenic acid metabolism. Am J Clin Nutr 1956;4: 420-33.

19 Hodges RE, Bean WB, Ohlson MA, et al. Human pantothenic acid deficiency produced by omegamethyl pantothenic acid. J Clin Invest 1959;38:1421-5.

20 Ralli EP, Dumm ME. Relation of pantothenic acid to adrenal cortical function. Vitam Horm 1953;11: 133-58. 